\title{
“O PROCESSO" DE FRANZ KAFKA E O QUE DIZ O DIREITO
}

\section{Camilla Amanda Aires de Medeiros}

Graduanda do curso de Direito da Universidade Federal do Rio Grande do Norte (UFRN). Ex-membro do Núcleo Urbano do Programa Motyrum de Educação Popular em Direitos Humanos (UFRN).

\section{REFERÊNCIA DA OBRA ANALISADA}

KAFKA, Franz. O Processo. 11 ed. São Paulo: Companhia de Bolso, 2005. Tradução e Posfácio de: Modesto Carone.

\section{APRESENTAÇÃO DO AUTOR}

Franz Kafka - nascido em 1883 e falecido em 1924 - foi um escritor tcheco de língua alemã tido como um dos maiores autores do século XX. Escrevia sobre a alienação e ansiedade do homem de seu tempo, além da fragilidade e impotência do mesmo diante do poder das instituições. Retratou situações incomuns com crueza e realismo. Nascido em Praga, pertencente à época ao Império Austro-húngaro, era filho de um comerciante judeu abastado e autoritário. $\mathrm{O}$ autor cresceu tendo como influências as culturas judaica, tcheca e alemã - sem se sentir pertencente a nenhuma delas integralmente. Declarou-se socialista e ateu durante a adolescência, chegando a participar de reuniões de grupos anarquistas; no fim da vida, por sua vez, viu-se sionista (PENSADOR, 2020).

Kafka se formou em Direito em Praga, no ano de 1906, fazendo, assim, a vontade de seu pai; trabalhando depois em companhias de seguro e, em paralelo, com literatura, sua verdadeira vocação. Afastou-se do trabalho por causa da tuberculose no ano de 1917 - alternou temporadas em sanatórios com trabalhos burocráticos, sem nunca deixar de escrever (chegou a dizer que tudo o que não era literatura o aborrecia (KAFKA apud ARIOCH, 2017)).

No fim da vida, pediu ao seu grande amigo Max Brod que queimasse todos os seus manuscritos depois de sua morte - o que, felizmente, não foi cumprido. 
| Revista Transgressões: ciências criminais em debate, v. 8, n. 1, julho de 2020

Praticamente desconhecido em vida, a maior parte das suas obras foram publicadas apenas após a sua morte - o qual foi o caso de "O Processo", um livro inacabado (PENSADOR, 2020).

\section{PERSPECTIVA TEÓRICA DA OBRA}

Sobre o contexto histórico de "O Processo", há dois fatos significativos para destacar: a crise dos anos 20 e a Primeira Grande Guerra Mundial. Tais acontecimentos fizeram surgir na sociedade da época uma sensação geral de ausência de lógica na existência humana - o que fez com que muitas pessoas, por sua vez, passassem a admitir as arbitrariedades do positivismo, as fraquezas das ciências e das epistemologias, e também o quão superficiais eram as teorias metafísicas que pretendiam explicar o mundo (TRINDADE, 2012).

Kafka encontrava-se dentro da postura ideológico-cultural chamada de Modernismo, que traduz, a nível internacional, os efeitos da modernização da vida sociocultural pós II Revolução Industrial, abordando tanto o comportamento como a psicologia dos indivíduos - o que fora uma nova forma do homem ocidental sentir a existência. Ao mesmo tempo que as grandes metrópoles da época passaram a oferecer oportunidades de crescimento pessoal, profissional, educacional e até mesmo romântico, também trouxeram consigo solidão, desconforto e crises existenciais - tais paradoxos são elementares para a Modernidade (GONZAGA, 2004).

Dentro deste cenário, a perspectiva jurídica assumida pela obra de Kafka pressupõe a culpabilidade do indivíduo, como em um sistema inquisitorial típico da Idade Média - em tese superada pela Declaração dos Direitos do Homem de 1789, filha da Revolução Francesa, por sua vez inspirada pelos ideais iluministas do século XVIII (VASCONCELOS; GURGEL, 2014). Há também uma forte referência aos Estados de exceção do início do século XX - Kafka usa a instituição jurídica como símbolo das transformações sociais e filosóficas da época em que vivia, acabando também por prever as tragédias que viriam a ocorrer nas próximas décadas (FIGUEIRA, 2008). Além disso, a própria experiência profissional do autor deu-lhe a ideia de que o ambiente jurídico é um grande sistema burocrático que desumaniza os agentes do poder 
| Revista Transgressões: ciências criminais em debate, v. 8, n. 1, julho de 2020

(RÊGO, 2014). “O Processo", publicado em 1925, faz uma crítica aos modelos jurisdicionais não humanistas e ao sistema punitivo estatal não garantista (VASCONCELOS; GURGEL, 2014).

\section{BREVE SÍNTESE DA OBRA}

Certa manhã, Josef K. é detido sem ter feito mal algum, de modo que o mesmo pensa ter sido caluniado ou então estar sofrendo alguma brincadeira dos colegas - eis o começo de uma das grandes obras de Franz Kafka, considerado um dos maiores escritores do século XX. Nesta, a luta do protagonista é descobrir pelo o que é acusado, quem o acusa e fundamentado em qual lei. Contudo, as forças do arbítrio não o permitem responder tais questionamentos (CARONE, 2005). Tudo beira ao surreal e à loucura.

K. era um funcionário exemplar que trabalhava em um grande banco e tinha um cargo de considerável responsabilidade em que gastava sua dedicação. Na manhã em que completou 30 anos, entretanto, foi detido por dois guardas em seu quarto guardas que desde logo pedem suborno. Assim, teve início uma mudança radical em sua vida, agora guiada por uma desventura burocrática interminável a fim de descobrir pelo o que era acusado. Pensou que esclareceria tudo durante o interrogatório, mas isso não aconteceu: o inspetor era rude e lhe fazia chantagens, e tanto ele quanto os guardas também desconheciam o motivo de sua detenção. O advogado contratado por K. acabou por ser dispensado ao não dar a atenção devida ao processo, e o protagonista também não conseguiu ter acesso ao judiciário durante a sua busca por justiça (BARDINE, 2020). Todo o processo parecia irreal e absurdo.

Josef K., que até então lutava para provar sua inocência pelo o que quer que fosse, perde as esperanças e fica apático sobre o processo que nada conhecia - sentindose, de fato, culpado. E, assim, foi condenado por um misterioso tribunal e executado por dois senhores um ano após o início do processo, nas vésperas de seus 31 anos (BARDINE, 2020): "Mas na garganta de K. colocavam-se as mãos de um dos senhores, enquanto o outro cravava a faca profundamente no seu coração e a virara duas vezes" (KAFKA, 2005, p. 228). Eis o fim de K.. 
| Revista Transgressões: ciências criminais em debate, v. 8, n. 1, julho de 2020

\section{PRINCIPAIS TESES DESENVOLVIDAS E REFLEXÃO CRÍTICA}

Dentro de uma atmosfera de absurdo existencial, há um sistema judiciário falho que ofende as garantias processuais elementares do cidadão. Sem haver qualquer acesso à Justiça, constrói-se na obra uma caricatura do sistema jurídico, suas instituições e protagonistas, pertencentes a uma justiça decadente e de discurso vazio (ACOSTA; CASTANHA, 2017). A Lei, pautada em relações de poder, e seu conteúdo são inatingíveis e secretos, servindo apenas para o espetáculo punitivista (RÊGO, 2014). O real discurso dessa instituição não visa à garantia de direitos ao processado; pelo contrário, trata-se de mera burocracia processual - ou seja, a figura humana é totalmente desrespeitada em seus direitos mais fundamentais em um processo, traduzindo-se a burocracia jurídica em mera forma de dominação.

K. é processado sem que o motivo seja revelado; não tem acesso ao próprio processo; o tribunal e até o advogado são inalcançáveis - desse modo, a própria defesa lhe é algo proibido, quando deveria ser plenamente disponível para si. Não se pôde derrubar as afirmações do acusador, nem sustentar a sua própria verdade, muito embora todos ao redor já pontuassem K. como culpado - mesmo sem se saber pelo o quê. Desde o início, portanto, não houve presunção de inocência para K., mas sim culpabilidade e parcialidade por essência.

O amadurecimento do ser humano ao longo de sua história embasou a criação de inúmeros princípios jurídicos, os quais estruturaram todo um modelo de Estado Democrático de Direito (PORFÍRIO, 2020), em que a lei delega competências e funções a cada órgão estatal de forma a servir à coletividade como um todo. São princípios que estão presentes nas mais diversas Constituições ao redor do mundo, delimitando a estrutura elementar do ordenamento jurídico de cada Estado (PORFÍRIO, 2020). O Estado Democrático de Direito trabalha com uma perspectiva diametralmente oposta às situações vividas na obra de Kafka em análise - pelo menos são materialmente distintas. A fim de limitar os poderes de punição exercidos pelo Estado, a presunção de inocência (in dubio pro reo) se faz indispensável - para garantir ao cidadão que este não seja 
| Revista Transgressões: ciências criminais em debate, v. 8, n. 1, julho de 2020 surpreendido com aparatos repressivos e secretos do Estado da mesma forma que acontecera a K..

Trata-se de paradigma já pontuado por Cesare Beccaria em 1764, ao dizer: "Ninguém pode ser condenado como criminoso até que seja provada sua culpa, nem a sociedade pode retirar-lhe a proteção pública até que tenha sido provado que ele violou as regras pactuadas" (BECCARIA apud OLIVEIRA, 2012, p.47). A condenação de um réu só pode se efetivar depois de corrido o devido processo legal, com todas as fases legítimas, pautadas em princípios próprios da ordem legal vigente, e dirigido por um juiz competente.

A Declaração Universal dos Direitos do Homem esclarece que "todo ser humano acusado de um ato delituoso tem o direito de ser presumido inocente até que a sua culpabilidade tenha sido provada, de acordo com a lei, em julgamento público no qual lhe tenham sido asseguradas todas as garantias necessárias à sua defesa" (1948, p. 7). A Constituição Federal brasileira coloca tal presunção como direito fundamental, presente no inciso LVII do artigo $5^{\circ}$, o qual diz que "ninguém será considerado culpado até o trânsito em julgado de sentença penal condenatória” (BRASIL, 1988 apud OLIVEIRA, 2017). Trata-se de um princípio que dá qualidade ao processo penal que o possui (LOPES JÚNIOR apud VASCONCELOS; GURGEL, 2014).

Além disso, o Estado não pode intervir na vida privada do indivíduo, a menos que a Lei expressamente o autorize a isso. O Princípio da Legalidade visa limitar o poder de punir do Estado, evitando assim um Estado arbitrário e com excesso de poder punitivo, obedecendo às exigências de justiça claras e necessárias para a paz social. Essa limitação do poder punitivo, como exigência indissociável de um Estado de Direito, é o que fundamenta a reserva legal - a qual garante a lei formal, de acordo com a matéria constitucional sobre o tema (BITENCOURT, 2014).

Há ainda que se falar na necessidade de se garantir o direito de defesa e de um julgamento feito por juiz natural legitimado constitucionalmente (OLIVEIRA, 2017) - o não cumprimento dessas garantias e de outras resulta na tragédia jurídica exemplificada pela obra kafkiana. O princípio dos atos processuais é indispensável para um devido processo legal - o qual, nesta obra, fora negado ao K. na medida em que ele não teve o direito de conhecer o que acontecia em seu próprio processo e ao não ter acesso a um contraditório equilibrado (BARRIONUEVO, 2018). 
| Revista Transgressões: ciências criminais em debate, v. 8, n. 1, julho de 2020

Outros princípios não atendidos foram o do contraditório e o da ampla defesa (artigo $5^{\circ}, \mathrm{LV}$, da Constituição Federal (BRASIL, 1988)). O contraditório se refere à garantia clara de dar ao acusado a oportunidade de tomar conhecimento prévio sobre as alegações da parte contrária para assim influenciar no livre convencimento do juiz (PATRIOTA, 2017). Já a ampla defesa dá ao processado o direito de defender seus interesses com argumentos ao seu favor e assim demonstrá-los, respeitando os limites legais (BARRINUEVO, 2018). Carazai entende tal princípio como “[...] a plena e completa possibilidade de o réu produzir provas contrastantes às da acusação, com ciência prévia e integral do conteúdo da acusação, comparecendo participativamente nos atos processuais, representado por defensor técnico" (apud PAVANI, 2016, p. internet). Foi atentado também o princípio da instrumentalidade das formas, o qual dispõe o processo apenas como meio de acesso à tutela jurisdicional, ou seja, como forma de garantir o direito material lesado - o qual deveria ser o foco da justiça (MARQUES; COSTA; OLIVEIRA, 2011). O princípio da jurisdicionalidade (nulla poena, nulla culpa sine iudicio), por sua vez, quer dizer mais do que apenas exigir a presença de um juiz em um processo; na verdade, exige um juiz imparcial, natural, competente e comprometido com a Constituição (LOPES JÚNIOR apud VASCONCELOS; GURGEL, 2014). Não se concretiza para o caso o princípio da imparcialidade do juiz, tendo em vista que os juízes do livro agem movidos por conveniências e não para a efetivação da justiça no caso concreto.

Impossível não citar ainda o princípio da publicidade processual, o qual diz que todos os atos processuais são públicos e disponíveis para o acesso de qualquer uma das partes, como por quem quer que esteja interessado (MALHEIROS, 2019). Trata-se de um princípio mitigado pela própria Constituição, no artigo 5, LX (BRASIL, 1988), ao falar que a publicidade pode ser barrada para a defesa da intimidade ou a certo interesse social - nestes casos, seguirão como segredo de justiça. Nestas circunstâncias, contudo, as partes e seus respectivos procuradores ainda podem consultar os autos (MALHEIROS, 2019) - ou seja, foi usurpado todo o direito de K. à publicidade processual de sua causa desconhecida. Afinal, trata-se de um Tribunal secreto, com autos processuais inacessíveis tanto ao acusado quanto à própria defesa; condena-se, assim, aquele que não sabe de nada. 
| Revista Transgressões: ciências criminais em debate, v. 8, n. 1, julho de 2020

Além desses, há também o princípio da verdade real, o qual, também afrontado na narrativa de "O Processo", de Kafka, exige a devida apuração dos fatos imputados. Antes de punir o processado, é preciso que haja provas que levem à justiça da causa - só assim se tem um julgamento justo (ESTRELA, 2017).

$\mathrm{O}$ princípio da isonomia, o qual busca garantir um tratamento igualitário e assim evitar discriminações, é ignorado diante do comportamento do Tribunal perante certas pessoas. Vê-se que o relacionamento próximo com funcionários da Justiça e juízes poderia refletir na absolvição do processado (MARQUES; COSTA; OLIVEIRA, 2011). O próprio K. tenta se aproximar de pessoas influentes que pudessem ajudar em sua defesa, como foi o que ocorrera com o Pintor, o qual garantia ter influências no mundo jurídico e ter como ajudá-lo em seu caso (MARQUES; COSTA; OLIVEIRA, 2011, p. 124). Ou seja, o processo também poderia ocorrer por trás do Tribunal público, nos corredores e até mesmo no ateliê do Pintor (KAFKA, 2005).

Importante falar sobre um grande princípio também ignorado ao longo da obra: o princípio da dignidade da pessoa humana, alicerce da nossa República, consagrado no artigo $1^{\circ}$, inciso III da Constituição Federal de 1988 (BRASIL, 1988). Com o mesmo busca-se, entre outras coisas, uma humanização do processo jurídico, o qual não deve ser estritamente técnico e seco, devendo-se sim considerar os impactos humanos da aplicação da lei. Observa-se assim, na obra "O Processo", a apresentação da justiça como algo inatingível e manipulável apenas por um determinado grupo de pessoas apáticas no que tange ao social (BARRINUEVO, 2018).

A crítica sobre o mundo jurídico vai além da supressão de garantias constitucionais de um Estado de Direito - o que já seria considerável e relevante. Além disso, de acordo com as conversas entre K. e o advogado, é denunciado que o resultado do processo dependeria indiscutivelmente das influências externas ao próprio processo, como já citado nessa resenha. $\mathrm{O}$ fundamento da lei, nessa perspectiva, vale menos do que as relações entre os indivíduos e as trocas de favores na hora de se decidir pela culpa ou não de um processado - relações não só entre integrantes do Poder Judiciário, mas também entre indivíduos anônimos e comuns. É como se a resolução jurídica de um processo precisasse de ajudas externas ao meio jurídico. Para influenciar nas decisões jurídicas, bastava participar das relações de poder próprias da sociedade - e não de um diploma de bacharel em Direito (RÊGO, 2014). 
| Revista Transgressões: ciências criminais em debate, v. 8, n. 1, julho de 2020

Com o Pintor influente no universo jurídico, K. aprende sobre os três tipos de absolvição:

\begin{abstract}
Esqueci de lhe perguntar primeiro que tipo de libertação deseja. Existem três possibilidades, ou seja, a absolvição real, a absolvição aparente e o processo arrastado. Naturalmente o melhor é absolvição real, só que não tenho a mínima influência sobre esse tipo de solução. Na minha opinião, não existe nenhuma pessoa que pudesse ter influência sobre a absolvição real [...]. Não sei de nenhuma absolvição real, mas sem dúvida de muitas formas de influência [...] e não presenciei uma só absolvição real [...]. A absolvição aparente e o processo arrastado. Só delas se pode tratar [...]. Ambas são alcançáveis com a minha ajuda, não sem esforço, é claro; neste aspecto, é que a absolvição aparente exige um esforço concentrado e temporário, e o processo arrastado um esforço muito menor, mas duradouro. [...] A absolvição aparente [...]. Os juízes inferiores, ou seja, aqueles que eu conheço, não têm o direito de absolver definitivamente; esse direito só o tem o tribunal supremo, inteiramente inacessível ao senhor, a mim e a todos nós. Não sabemos como as coisas se passam ali, nem tampouco queremos saber, diga-se de passagem. [...] O Processo arrastado consiste em que o procedimento judicial é mantido de forma permanente no estágio inferior do processo. Para alcançar isso, é necessário que o acusado e seu protetor especialmente este - fiquem em contato pessoal ininterrupto com o tribunal. [...]. O processo precisa girar continuamente no pequeno círculo em que está encerrado de modo artificial (KAFKA, 2005, p. 152-161).
\end{abstract}

A passagem transcrita mostra o drama que passa a ser a vida de quem é processado, sem a chance real de ver-se livre da acusação, que o atinge em todos os aspectos da vida. Não há como ser inocentado de fato, nem como seguir em frente com a própria vida. A pessoa passa a ser vítima de estigmas do "ser processado" e o juiz afeito a preconceitos e influências que não deveriam tocá-lo na hora de decidir um processo.

Kafka põe todos que estão à volta do protagonista em um patamar de descrédito e surrealismo: o inquérito ocorre em um aposento nos fundos de uma casa miserável; os cartórios estão localizados dentro de sótãos de casebres; e o advogado encontra-se com clientes na própria cama. Trata-se de um mundo em que os Juízes "superiores" estão presentes apenas no imaginário do povo. Os próprios tribunais localizam-se no interior de casas populares - a Justiça está, na verdade, espalhada por todos os cantos, até nos mais improváveis (RÊGO, 2014). Tudo é o Tribunal e a este tudo pertence.

O que acontece no livro é que ninguém consegue ter o devido acesso às instituições superiores do Judiciário - nem mesmo os advogados e os juízes conseguem. Todos desconhecem suas regras e seus verdadeiros participantes (FIGUEIRA, 2008). 
| Revista Transgressões: ciências criminais em debate, v. 8, n. 1, julho de 2020

Contudo, para justificar o sistema em que estavam inseridos, o Sacerdote conta a K. a parábola do porteiro da lei e do homem do campo, a qual diz assim:

\begin{abstract}
Nos textos introdutórios à lei consta o seguinte [...]: Diante da lei está um porteiro. Um homem do campo dirige-se a este porteiro e pede para entrar na lei. Mas o porteiro diz que agora não pode permitir-lhe a entrada. O homem do campo reflete e depois pergunta se não pode entrar mais tarde. "É possível", diz o porteiro, "mas agora não." Uma vez que a porta da lei continua como sempre aberta, e o porteiro se põe de lado, o homem se inclina para olhar o interior através da porta. Quando nota isso, o porteiro ri e diz: "Se o atrai tanto, tente entrar apesar da minha proibição. Mas veja bem: eu sou poderoso. E sou apenas o último dos porteiros. De sala para sala, porém, existem porteiros cada um mais poderoso que o outro. Nem mesmo eu posso suportar a visão do terceiro". O homem do campo não esperava tais dificuldades: a lei deve ser acessível a todos e a qualquer hora, pensa ele; agora, no entanto, ao examinar mais de perto o porteiro [...], ele decide que é melhor aguardar até receber permissão de entrada. O porteiro lhe dá um banquinho e deixa-o sentar-se ao lado da porta. Ali fica sentado dias e anos. Ele faz muitas tentativas para ser admitido, e cansa o porteiro com os seus pedidos. Muitas vezes o porteiro submete o homem a pequenos interrogatórios, pergunta-lhe a respeito da sua terra e de muitas outras coisas, mas são perguntas indiferentes, como as que costumam fazer os grandes senhores, e no final repete-lhe sempre que ainda não pode deixá-lo entrar. O homem, que havia se equiparado para a viagem com muitas coisas, lança mão de tudo, por mais valioso que seja, para subornar o porteiro. Este aceita tudo, mas sempre dizendo: "Eu só aceito para você não achar que deixou de fazer alguma coisa". Durante todos esses anos, o homem observa o porteiro quase sem interrupção. [...] Nos primeiros anos, amaldiçoa em voz alta o acaso infeliz; mais tarde, quando envelhece, apenas resmunga consigo mesmo. [...] Antes de morrer, todas as experiências daquele tempo convergem na sua cabeça para uma pergunta que até então não havia feito ao porteiro. [...] "O que é que você ainda quer saber?", pergunta o porteiro [...]. "Todos aspiram a lei", diz o homem. "Como se explica que, em tantos anos, ninguém além de mim pediu para entrar?" O porteiro percebe que o homem já está no fim, e para ainda alcançar sua audição em declínio, ele berra: "Aqui ninguém mais podia ser admitido, pois esta entrada estava destinada só a você. Agora eu vou embora e fecho-a" (KAFKA, 2005, p. 214-215).
\end{abstract}

O acesso à lei não é algo que se cumpre facilmente. Entende-se, portanto, que nesta narrativa a lei não deve ser compreendida, apenas servida - a qual, por sua vez, não serve à justiça, mas somente ao puro procedimento sem conteúdo. A Lei pela Lei. As instituições estão muito acima dos indivíduos, que devem estar totalmente entregues às mesmas e às suas arbitrariedades. Nota-se que o próprio porteiro não tinha conhecimento sobre o interior da Lei. Após a conversa com o Sacerdote, Josef K. teve sua morte moral ao aceitar o sistema, abandonando seus questionamentos acerca de uma justiça inatingível (FIGUEIRA, 2008).

Observa-se, dentro da atmosfera do absurdo, também a perda dos direitos de personalidade. Segundo Francisco Amaral (apud GONÇALVES, 2014, p. 186), os 
| Revista Transgressões: ciências criminais em debate, v. 8, n. 1, julho de 2020 direitos da personalidade podem ser definidos como "direitos subjetivos que têm por objeto os bens e valores essenciais da pessoa, no seu aspecto físico, moral e intelectual". Os direitos da personalidade são prerrogativas individuais, direitos inalienáveis, inerentes à pessoa humana, e merecem proteção legal, como a proteção à intimidade do ser humano, à sua imagem, ao seu corpo, à sua dignidade e até ao seu próprio nome. Assim, tais direitos estão protegidos, na legislação brasileira, do artigo 11 ao artigo 21 do Código Civil de 2002. Além disso, são expressamente citados no artigo $5^{\circ}, \mathrm{X}$, da Constituição Federal de 1988 (GONÇALVES, 2014, p. 184-186).

No caso do livro, o direito de personalidade atacado é o próprio nome do protagonista: Josef K. - nota-se a ausência de um sobrenome completo, abreviado apenas pela primeira letra do mesmo. Ao longo da obra ele é praticamente referenciado apenas como K.. Vê-se, assim, que o processo que o atinge afeta também o seu nome e a sua própria personalidade, levando a um procedimento de desumanização, a uma perspectiva de não cidadão. K., ao ser executado, vê-se como um cão, cuja concepção pejorativa dá a ideia de pessoa infame. De todo modo, tal abreviação também lhe retira, além da identidade, a sua própria linhagem familiar (ROCHA, s.d.). Josef K. é, portanto, um despersonalizado para o Estado que o rege, sem personalidade civil - tão sem conteúdo quanto a Lei que o condenou. O processo precisa de culpados tão vazios quanto o mesmo.

Importante dizer que, para muitos indivíduos com menores níveis de instrução e de renda, ao precisarem entrar em contato com o universo jurídico, o processo pode portar características kafkianas - mesmo num tido Estado Democrático de Direito, de concepção distante do contexto em que a obra escrita por Kafka foi elaborada. Existem inegáveis problemas na hora de concretização das leis fundamentais nos casos concretos. E há ainda a divisão entre leigos (à margem do direito) e "iniciados" no mundo jurídico, os quais muitas vezes ignoram as necessidades imediatas dessa população mais carente e fazem do Direito algo cada vez mais distante do cidadão comum, prendendo aquele em uma ritualística vazia e fria (FIGUEIRA, 2008).

Segundo o professor Arnaldo Moraes Godoy, "a Literatura traduz o que a sociedade pensa sobre o Direito. A literatura de ficção fornece subsídios para compreensão da Justiça e de seus operadores" (2003, p.134). Ou seja, Kafka criticamente tece uma narrativa sobre a violação do direito de defesa, o monopólio do 
| Revista Transgressões: ciências criminais em debate, v. 8, n. 1, julho de 2020 direito por e para alguns, assim como a própria desumanização da Justiça diante do poder de punir. Em pleno século XXI, eventos semelhantes ocorrem em diversos locais do mundo, por meio de leis arbitrárias e de um acesso à justiça inatingível para parte dos indivíduos, que tem desrespeitado perante si o princípio sagrado da dignidade humana.

\section{CONCLUSÃO}

Através do irreal, Kafka cria uma trama que evidencia a importância de um devido processo legal para a efetivação da justiça, revelando o que acontece quando princípios como o Contraditório, a Ampla Defesa, a Presunção de Inocência, o Princípio da Legalidade, o Princípio dos atos processuais, o Princípio da Imparcialidade do Juiz, o Princípio da Publicidade Processual, o Princípio da Verdade Real, o Princípio da Isonomia e o essencial Princípio da Dignidade da Pessoa humana são ignorados em prol de uma burocracia vazia que apenas visa a dominação social - havendo, portanto, uma crítica contundente a um ambiente jurídico que suprime as garantias constitucionais de um Estado Democrático de Direito. Fala-se, ainda, e, por sua vez, se condena as influências externas ao andamento de um processo e a despersonalização do indivíduo durante esse mesmo processo. A Lei pela Lei não se importa com justiça, apenas com o vazio de um Estado sem razões para ser.

Segundo o professor Arnaldo Moraes Godoy, “a Literatura traduz o que a sociedade pensa sobre o Direito. A literatura de ficção fornece subsídios para compreensão da Justiça e de seus operadores" (2003, p. 134). Ou seja, Kafka criticamente tece uma narrativa sobre a violação do direito de defesa, o monopólio do direito por e para alguns, assim como a própria desumanização da Justiça diante do poder de punir. Em pleno século XXI, eventos semelhantes ocorrem em diversos locais do mundo, por meio de leis arbitrárias e de um acesso à justiça inatingível para parte dos indivíduos, que tem desrespeitado perante si o princípio sagrado da dignidade humana. 
| Revista Transgressões: ciências criminais em debate, v. 8, n. 1, julho de 2020

\section{REFERÊNCIAS}

ACOSTA, Daniel Yamauchi; CASTANHA, Ruth Faria da Costa. Direito, justiça e mito: uma leitura a partir de "O processo", de F. Kafka. Anamorphosis: Revista Internacional de Direito e Literatura, [s.1.], v. 2, n. 3, p.437-464, 2017. Disponível em: https://dialnet.unirioja.es/servlet/articulo?codigo=6255928. Acesso em: 21 mar. 2020.

ARIOCH, David. A ansiedade social de Kafka. 2017. Disponível em:

https://editoras.com/a-ansiedade-social-de-kafka/. Acesso em: 02 abr. 2020.

BARDINE, Renan. O Processo - Franz Kafka. [s.d.]. Disponível em: https://www.coladaweb.com/resumos/o-processo-franz-kafka. Acesso em: 20 mar. 2020.

BARRIONUEVO, Thainá de Paiva. Os princípios processuais constitucionais e a obra "O Processo" de Franz Kafka. Revista de Direito Público da Procuradoria-geral do Município de Londrina, Londrina, v. 1, n. 7, p.75-85, 2018. Disponível em: http://www.aprolon.com.br/pkp/ojs/index.php/rdp-pgmlondrina/article/view/153/103. Acesso em: 22 mar. 2020.

BITENCOURT, Cezar Roberto. Fundamentos e História do Direito Penal: Princípios limitadores do Poder Punitivo Estatal. In: BITENCOURT, Cezar Roberto. Tratado de Direito Penal: parte geral. Parte Geral. 20. ed. São Paulo: Saraiva, 2014. Cap. 2. p. 4971.

BRASIL. Constituição (1988). Constituição da República Federativa do Brasil: promulgada em 5 de outubro de 1988. Constituição (1988). Disponível em: http://www.planalto.gov.br/ccivil_03/constituicao/constituicaocompilado.htm. Acesso em: 20 mar. 2020.

CARONE, Modesto. Posfácio: Um dos maiores romances do século. In: KAFKA, Franz. O Processo. 11. ed. São Paulo: Companhia de Bolso, 2005. p. 257-270. Tradução e Posfácio de: Modesto Carone.

DECLARAÇÃO UNIVERSAL DOS DIREITOS DO HOMEM. Assembleia Geral das Nações Unidas em Paris. 10 dez. 1948. Disponível em: https://nacoesunidas.org/wpcontent/uploads/2018/10/DUDH.pdf. Acesso em: 20 mar. 2020.

ESTRELA, Wallace. O princípio da verdade real no âmbito do Processo Penal. Disponível em: https://wallacestrela.jusbrasil.com.br/artigos/456090513/o-principio-daverdade-real-no-ambito-do-processo-penal. Acesso em: 22 mar. 2020.

FIGUEIRA, Felipe Gonçalves. Estado e Direito na representação estética de Kafka. 2008. 60 f. TCC (Graduação) - Curso de Direito, Centro de Ciências Jurídicas e Econômicas, Universidade Federal do Rio de Janeiro, Rio de Janeiro, 2008. Disponível em: https://pantheon.ufrj.br/bitstream/11422/9391/1/FGFigueira.pdf. Acesso em: 20 mar. 2020. 
| Revista Transgressões: ciências criminais em debate, v. 8, n. 1, julho de 2020

GONÇALVES, Carlos Roberto. Dos Direitos da Personalidade. In: GONÇALVES, Carlos Roberto. Direito Civil brasileiro: parte geral. Parte Geral. 3. ed. São Paulo: Saraiva, 2014. p. 184-186.

GODOY, A. M. Direito e literatura. Revista CEJ, v. 7, n. 22, p. 133-136, 2 set. 2003. Disponível em: https://revistacej.cjf.jus.br/revcej/article/view/573. Acesso em: 20 mar.2020.

GONZAGA, S. O sentido do modernismo, 2004. Disponível em: https://educaterra.terra.com.br/literatura/modernismo/2004/05/17/001.htm. Acesso em: 20 mar.2020.

KAFKA, Franz. O Processo. 11. ed. São Paulo: Companhia de Bolso, 2005. Tradução e Posfácio de: Modesto Carone.

MALHEIROS, Nayron Divino Toledo. Da Publicidade dos Atos Processuais no NCPC. Disponível em: https://nayron.jusbrasil.com.br/artigos/683446603/dapublicidade-dos-atos-processuais-no-ncpc. Acesso em: 21 mar. 2020.

MARQUES, Camila Facchin; COSTA, Izabella Affonso; OLIVEIRA, Julia Santos de. Os princípios processuais na obra "O Processo" de Franz Kafka. Direito e Sociedade: Revista de Estudos Jurídicos e Interdisciplinares, Catanduva, v. 6, n. 1, p.120-133, 2011. Disponível em:

http://unifipa.com.br/site/documentos/revistas/direito/dir_2011_vol6_n1.pdf\#page=120. Acesso em: 20 mar. 2020.

OLIVEIRA, Raphael Henrique Figueiredo de. Kafka penalista: da ficção literária à realidade penal. Anamorphosis: Revista Internacional de Direito e Literatura, [s.l.], v. 3, n. 2, p.411-435, 2017. Disponível em: https://dialnet.unirioja.es/servlet/articulo?codigo=625592521. Acesso em: 21 mar. 2020.

PATRIOTA, Caio César Soares Ribeiro. Princípio da contraditório e da ampla defesa. Revista Jus Navigandi, p. 1-1, fev. 2017. Disponível em: https://jus.com.br/artigos/56088/principio-da-contraditorio-e-da-ampla-defesa. Acesso em: 22 mar. 2020.

PAVANI, Alex Roni Alves. O princípio da ampla defesa e seus aspectos. Revista Jus Navigandi, p. 1-5, nov. 2016. Disponível em: https://jus.com.br/artigos/53601/oprincipio-da-ampla-defesa-e-seus-aspectos\#_ftn2. Acesso em: 22 mar. 2020.

PENSADOR. Biografia de Franz Kafka. Disponível em: https://www.pensador.com/autor/franz_kafka/biografia/. Acesso em: 20 mar. 2020.

PORFÍRIO, Francisco. Estado Democrático de Direito. Brasil Escola. Disponível em: https://brasilescola.uol.com.br/sociologia/estado-democratico-direito.htm. Acesso em 22 de março de 2020. 
| Revista Transgressões: ciências criminais em debate, v. 8, n. 1, julho de 2020

RÊGO, Eduardo de Carvalho. O Tribunal Kafkiano e os seus juristas: quem diz o Direito em O Processo?. Anais do II CIDIL, Passo Fundo, v. 2, n. 1, p.1-18, jul. 2014. Disponível em: http://seer.rdl.org.br/index.php/anacidil/article/view/156/230. Acesso em: 20 mar. 2020.

RIBAS, Luciana Marin; MAGNANI, Nathércia Cristina Manzano. O Sistema Penal brasileiro e a obra de Kafka. Anais do I CIDIL, Passo Fundo, v. 1, n. 1, p.1-15, nov. 2012. Disponível em: http://rdl.org.br/seer/index.php/anacidil/article/view/140/214. Acesso em: 22 mar. 2020.

ROCHA, Marisa. KAFKA E O PROCESSO: da despersonalização à práxis —modos de reflexão. Athos e Ethos, Patrocínio, [s.v], [s.n.], p.1-14, [20-]. Disponível em: http://www.unicerp.edu.br/images/revistascientificas/athoseethos/3\%20\%20KAFKA\%20E\%20O\%20PROCESSO $\% 20 \mathrm{da} \% 20$ despersonaliza $\%$ C3\%83\%C2\%A 7\% $3 \% 83 \% \mathrm{C} 2 \% \mathrm{~A} 3 \mathrm{o} \% 20 \% \mathrm{C} 3 \% 83 \% \mathrm{C} 2 \% \mathrm{~A} 0 \% 20 \mathrm{pr} \% \mathrm{C} 3 \% 83 \% \mathrm{C} 2 \% \mathrm{~A} 1 \times \mathrm{xis} \% 20 \% 20$ $\% 20$ modos\%20de\%20reflex\%C3\%83\%C2\%A3o.pdf. Acesso em: 20 mar. 2020.

TRINDADE, André Karam. 12.KAFKA E OS PARADOXOS DO DIREITO: DA FICÇÃO À REALIDADE. Revista Diálogos do Direito - Issn 2316-2112, [s.l.], v. 2, n. 2, p.137-160, 16 nov. 2012. Cesuca - Centro Ensino Superior de Cachoeirinha. http://dx.doi.org/10.17793/rdd.v2i2.63. Disponível em: http://ojs.cesuca.edu.br/index.php/dialogosdodireito/article/view/63. Acesso em: 20 mar. 2020.

TRINDADE, André Karam. Kafka desnuda os paradoxos do Direito. 2012. Disponível em: https://www.conjur.com.br/2012-out-13/diario-classe-kafka-desnudaparadoxos-direito. Acesso em: 22 mar. 2020.

VASCONCELOS, Guilherme Mantovani; GURGEL, Maria Antonieta Rigueira Leal. Ofensa às garantias processuais do cidadão em face da obra (do livro) "O Processo", de Franz Kafka. Anais Simpac, Viçosa, v. 1, n. 6, p.441-446, 2014. Disponível em: https://academico.univicosa.com.br/revista/index.php/RevistaSimpac/article/view/437. Acesso em: 20 mar. 2020. 